\title{
Safety Evaluation of Accident-Tolerant FCM Fueled Core with SiC-coated Zircalloy Cladding for Design-Basis-Accidents and Beyond DBAs
}

Ji-Han Chun*, Sung-Won Lim, Bub-Dong Chung, and Won-Jae Lee

Korea Atomic Energy Research Institute

*Corresponding author : Ji-Han Chun

Address: Daedeok-daero 989-111, Dukjin-dong, Yuseong-gu,Daejeon, Korea

Phone: +82-42-868-8915

Email: chunjh@kaeri.re.kr

\begin{abstract}
The FCM fueled cores proposed as an accident tolerant concept is assessed against the design-basis-accident (DBA) and the beyond-DBA (BDBA) scenarios using MARS code. A thermal conductivity model of FCM fuel is incorporated in the MARS code to take into account the effects of irradiation and temperature that was recently measured by ORNL. Preliminary analyses regarding the initial stored energy and accident tolerant performance were carried out for the scoping of various cladding material candidates.

A 16x16 FA with SiC-coated Zircalloy cladding was selected as the feasible conceptual design through a preliminary scoping analysis. For a selected design, safety analyses for DBA and BDBA scenarios were performed to demonstrate the accident tolerance of the FCM fueled core. A loss of flow accident (LOFA) scenario was selected for a departure-from-nucleate-boiling (DNB) evaluation, and large-break loss of coolant accident (LBLOCA) scenario for peak cladding temperature (PCT) margin evaluation. A control element assembly (CEA) ejection accident scenario was selected for peak fuel enthalpy and temperature. Moreover, a station blackout (SBO) and LBLOCA without a safety injection (SI) scenario were selected as a BDBA. It was demonstrated that the DBA safety margin of the FCM core is satisfied and the time for operator actions for BDBA $\mathrm{s}$ is evaluated.
\end{abstract}

Keywords: FCM fuel, SiC-coated zircalloy cladding, MARS code 


\section{Introduction}

The Fukushima nuclear accident of March 11, 2011 revealed a significant weakness of the LWR $\mathrm{UO}_{2}$ fuelZircalloy cladding system, in which the fuel rods were severely damaged. Even though there are many various engineered safety features, the adequate decay heat removal was not maintained with the total loss of all electric powers. As a consequence, the cladding damage and fuel meltdown could not be avoided, and the explosion of hydrogen resulting from the Zircalloy cladding oxidation caused a massive destruction of the reactor building (Baba, 2013).

After the Fukushima accident, the efforts to overcome this weakness of existing LWRs were introduced, such as a change of the fuel and cladding materials, an introduction of new safety features, the turning concept of the safety feature to a passive system, and so on. One of these efforts is a consideration of Fully Ceramic Microencapsulated (FCM) replacement fuel into LWRs (Terrani, 2012).

A FCM fuel pellet consists of Tri-isotropic (TRISO) particle fuel highly packed in a dense Silicon-Carbide (SiC) matrix with stainless steel (SS) or Silicon Carbide $(\mathrm{SiC})$ cladding rather than a conventional Zircalloy cladding, as shown in Fig. 1 (Lee, 2013). The accident tolerant features of the FCM fuel can be summarized as: 1) resistance to radioactivity release by the TRISO particle and additionally by the SiC pellet matrix. In addition, the fission product retention by the TRISO particles and SiC matrix reduces the fuel rod internal pressure and subsequent mechanical stress to the cladding; 2) resistance to fuel thermo-mechanical degradation by high heat conductivity of a $\mathrm{SiC}$ pellet, which can result in lowering the fuel centerline temperature and temperature gradient during normal and accident conditions; 3) resistance to hydrogen production using accident-tolerant cladding materials such as $\mathrm{SS}$ or $\mathrm{SiC}$, which have a lower water-steam reaction rate, and thus a lower hydrogen generation rate than the conventional Zircalloy cladding; and 4) resistance to nuclear proliferation by the complexity of Plutonium extraction from the spent FCM fuel pellet and TRISO particles.

The TRISO particle fuel, which has been experienced and well-proven in the various High Temperature Gas Cooled Reactor (HTGR) programs and recently re-qualified by the DOE Next Generation Nuclear Plant (NGNP) program, shows excellent performance in radioactivity resistance capability through the presence of multiple layers of ceramic coating, which are chemically stable and mechanically strong at high temperature and high burnup conditions (Pappano, 2008; Petti, 2012).

The project entitled "Fully Ceramic Microencapsulated (FCM) Replacement Fuel for LWRs," funded by the Korea and US joint I-NERI program, is in progress. The objective of the project is to assess the feasibility of replacing the conventional $\mathrm{UO}_{2}$ fuel assemblies (FAs) of the existing fleet of LWRs with accident-tolerant FCM FAs. The project involves FCM fuel qualification including the manufacture of FCM fuel samples and a postirradiation examination by the US side, as well as a neutronics exploration, thermal-hydraulic assessment, and safety assessment of the FCM fueled core by the Korea side (Lee, 2014).

In the paper, the safety of the FCM fueled core is assessed by accident analysis through modeling thermal conductivity based on FCM fuel qualification and adopting conservative core physics data from neutronics exploration. The design of the safety margins were evaluated for the following DBA scenarios: the loss of flow 
accidents for the DNB margin evaluation, and the loss of coolant accidents for the peak cladding temperature (PCT) margin evaluation. Moreover, the accident analysis for the beyond-DBA scenarios such as SBO and multiple safety system failures were performed to demonstrate the accident-tolerant envelope of the FCM fueled core.

\section{Analysis Methodologies}

\subsection{Thermal conductivity prediction modeling for FCM fuel}

In the safety analysis, the thermal conductivity of the fuel is very important for the estimation of the RCS performance. Safety parameters such as the peak cladding temperature during an LBLOCA and the fuel enthalpy of a CEA ejection accident are strongly related to the fuel thermal conductivity as well as the initial stored energy in the steady state.

The FCM fuel pellet is non-uniformly composed of various materials, as mentioned in the Introduction. Among these materials, $\mathrm{SiC}$ is dominant in the determination of the thermal conductivity and thermal conductivity is strongly related to the molecular structure of the material. Since the molecular structure can change through the irradiation, the thermal conductivity may change significantly by the irradiation. ORNL provided experimental data about the thermal conductivity of non-irradiated and irradiated FCM fuel (Ott, 2013).

From Fig. 2, degradation and recovery phenomena on the thermal conductivity can be identified. The molecular structure of FCM fuel is damaged by the irradiation dose. On the other hand, the damaged molecular structure is re-ordered at a high-temperature condition. According to the degradation effect by irradiation and recovery effect by temperature, the thermal conductivity of the FCM fuel is changed. Fig. 2 presents that irradiated thermal conductivity increases with temperature.

However, Fig 3 shows irradiated thermal conductivity slightly decreases with temperature, which also is provided by ORNL. The different trends between these two figures come from experimental condition. In the former conductivity, the measured temperature is identical with the irradiated temperature. It means the damaged molecular structure has enough time to be re-ordered at a high temperature On the other hand, the latter thermal conductivity is measured for various temperatures after irradiation at a certain temperature. It means Fig. 3 has no recovery effect. The main idea for modeling thermal conductivity is that the experimental data from Fig. 2 is appropriate for applying to steady state and Fig. 3 can be applied to transient calculation because the time duration for the transient of each accident scenario is not enough to recover the molecular structure.

Thermal conductivity modeling for FCM fuel is formulated from the previous experimental findings. The modeling is based on the following equation for the thermal conductivity of irradiated SiC (LANCE, 2009). In the equation, the degradation effect is defined as the thermal defect resistance (TDR).

$$
\operatorname{TDR}=\frac{1}{K_{i r r}}-\frac{1}{K_{n e n-i r r}}
$$


The equation was developed to identify the degradation effect. However, the equation also can be available to identify both the degradation and recovery effect. The degradation and recovery effect are compatible factors for a thermal conductivity change. Thus, the effect of irradiation and temperature can be merged into one parameter. The merged parameter is defined as the Effective TDR (TDRe) in this study.

From the definition of effective TDR, the modeling is expressed by following set of equations. The equations for the thermal conductivity of non-irradiated FCM fuel and effective TDR are generated from ORNL experimental data. According to the data, the degradation effect is eliminated and the value of the effective TDR becomes zero when the fuel temperature exceeds $1400 \mathrm{~K}$. Fig. 3 compares the predicted thermal conductivity of FCM fuel with the experimental results.

$$
K_{\mathrm{FCM}}=\left(\frac{1}{\mathrm{~K}_{\operatorname{man}-i \pi r}}+\mathrm{TDR}_{E}\right)^{-1}
$$

(2)

$$
\begin{aligned}
& \mathrm{K}_{\text {non-irr }}=43.9582-0.04264 *(\mathrm{t}-1000.0)+4.11495 \times 10^{-5} *(\mathrm{t}-1000.0)^{2} \\
& -2.2601310^{-9} *(t-1000.0)^{3}+5.5732810^{-11} *(t-1000.0)^{4} \\
& \operatorname{TDR}_{*}=0.4112-9.4749810^{-4} * t+9.2825810^{-7} * t^{2}-4.3892910^{-10} * t^{3} \\
& +7.8756510^{-14} * t^{4}(t<1400 \mathrm{~K})
\end{aligned}
$$

The conductivity modeling is established as below:

- For the steady state calculation, it is assumed for an infinite operation and thermal conductivity of FCM fuel is calculated from suggested set of equations.

- For the transient analysis, TDRe is calculated from the steady state temperature and the values are fixed during the transient analysis. Then, the thermal conductivity of FCM fuel is calculated with fixed TDRe and decreases only with a temperature increase.

Fig. 4 shows the thermal conductivity modeling of FCM fuel.

\subsection{Analysis code and system modeling}

Computer codes are used to carry out the accident analysis during the normal and accident conditions. The analyses of accident scenarios, which are classified into anticipated operational transients, accidents, and beyond-DBA, are performed using the MARS code. The backbones of MARS are RELAP5/MOD3.2.1.2 (RELAP5, 1995) and COBRA-TF (Thurgood, 1983) codes of USNRC. The RELAP5 code is a versatile and robust system analysis code based on a one-dimensional two-fluid model for two-phase flows, whereas the COBRA-TF code is based on a 3-D, 2-fluid, 3-field model. The two codes were consolidated into a single code 
by integrating the hydrodynamic solution schemes, and unifying various thermal-hydraulic models, EOS and I/O features. The sources of the codes were fully restructured using the modular data structure and a new dynamic memory allocation scheme of FORTRAN 90. In addition, a generic multidimensional fluid model has been developed and implemented to the RELAP5 system analysis module in order to overcome some limitations of the COBRA-TF 3D vessel module. The last version of this series is MARS3.1 (KAERI, 2009), which was released in 2005. MARS3.1 can be utilized for the simulation of DBA transients such as a loss of coolant, anticipated transients without scram (ATWS), and operational transients such as a loss of flow, loss of feedwater, loss of offsite power, and turbine trip. Since the beginning of the 2000s, MARS code has been well validated through lots of assessment activities and utilizations (Lee, 2003; Lee 2013).

The new capability for FCM fuel analysis was implemented by adding the functional form of FCM conductivity property change during a transient, as described in the previous section. To determine the DNB margin evaluation, a CE-1 correlation has been implemented into the new version. Fig. 5 shows the one-dimensional nodalization of an OPR-1000 for a safety analysis. The core consists of two channels, a hot core channel and average core channel. The hot core channel includes the hottest fuel and hot fuel. The hottest fuel models a single hottest fuel rod and the hot fuel rod models rods in a single hottest assembly. Other rods are modeled as the average rod in the average core channel.

\section{Preliminary Scoping Analysis of FCM fueled Core}

In order to select most feasible fuel assembly and cladding material of FCM fueled core, a scoping analysis has been performed to have a relative comparison of the FCM fueled cores with the reference OPR-1000 UO $/ 2 \mathrm{Zr}$ fueled core using five candidates, as shown in Table 1. The 16x16 and 12x12 structures are selected as candidates for fuel assembly. In order to replace Zircalloy cladding which could generate lots of hydrogen in the accident condition, we select stainless steel (SS) and SiC. SiC coated Zircalloy cladding ( $\mathrm{SiC} / \mathrm{Zr}$ ) also is considered as an alternative cladding material. SiC coating is expected to be a protective layer from Zircalloy and water reaction.

The effect on the initial stored energy and the accident tolerant performance are considered in the scoping analysis to select most feasible candidate.

A steady state analysis was performed to estimate the initial stored energy for each candidate FCM fuel. Fig. 6 shows the comparison of centerline temperatures during full power operation for the different types of FCM fuel assemblies. A centerline temperature can reflect initial stored energy and a higher initial stored energy would be expected to be worse result during the accidents. Since a 12x12 fuel assembly has a smaller number of rods and higher power per rod than a 16x16 fuel assembly, it has a higher centerline temperature and initial stored energy. The initial stored energy of $\mathrm{SiC}$ cladding in this figure is higher than SS cladding cases. When SiC is manufactured as the cladding material, a fiber-type $\mathrm{SiC}$ is wound around the fuel pellet. The thermal conductivity of fiber-type $\mathrm{SiC}$ is very low, and it is weakness of $\mathrm{SiC}$ as cladding material from the view point of the initial stored energy (Stempien, 2011). Thus, the FCM fuel with a 12x12 fuel assembly or SiC cladding may have some disadvantages in terms of the initial stored energy. 
In the view point of initial stored energy, 16x16 FA with SS shows the best performance. However, we considered stainless steel 304 as SS cladding and the oxidation rate of 304 SS is as large as Zircalloy, and even larger than Zircalloy at high temperature as shown in the Fig. 7 from an experiment of ORNL (Terrani, 2014). Therefore, the most feasible candidate is FCM fuel with a 16x16 fuel assembly with SiC coated Zircalloy cladding. This candidate was used in the following safety analyses.

\section{Safety Analysis in FCM Fueled Core}

\subsection{Selection of Scenario and Acceptance Criteria}

The objective of the safety analysis is to demonstrate that a plant loaded by FCM fuel meets the safety requirements and acceptance criteria during anticipated operational occurrence (AOO)s or accidents. Accidents are further subdivided into DBA, beyond-DBA, and severe accident (SA) according to their frequency of occurrence and acceptance criteria of integrity of the barriers. Although the full spectrum of consequences, from transients to DBAs to SAs, should be considered to assess the safety of FCM fueled core, typical accident scenarios of each category have been selected to demonstrate the integrity of FCM fueled core.

The selected scenario for AOO is a total LOFA to confirm the DNB margin of FCM fueled core. As a limiting DBA scenario, a LBLOCA scenario is selected to check the integrity of fuel cladding material in a heat-up case. CEA ejection accident is also selected as DBA to check the pellet cladding mechanical interaction (PCMI) integrity of FCM fuel. In addition to DBA, beyond-DBAs such as SBO and LBLOCA without safety injection scenario are considered to demonstrate the accident-tolerant envelop of the FCM fuel. Fuel integrity criteria used for the safety analysis of NPP are presented in Table 2. The current acceptance criteria of $\mathrm{UO}_{2} /$ Zircalloy fuel were well specified in regulatory documents; however, the FCM acceptance criteria during accidents are not well known yet. In this work, the energy deposition criteria for FCM fuel integrity during a CEA ejection accident was chosen as the same value of $\mathrm{UO}_{2} /$ Zircalloy fuel. The melting temperature of FCM was selected as $3003 \mathrm{~K}$, which is a melting temperature of $\mathrm{SiC}$ matrix. The preliminary criteria in Table 2 should be validated and replaced with the new acceptance criteria through the extensive experiment programs.

\subsection{Initial Conditions and Input Parameters}

For the safety assessment, each event discussed in this report has been analyzed for normal operation conditions. The core physics parameters were generated by a 3D calculation for all fuel cycles (Lee, 2013). To be conservative, the most limiting value for each core physics parameter was selected in the safety analysis.

The inherent characteristics of FCM fuel are assessed on the conditions and parameters. These initial conditions and input parameters are listed in Table 3:

- The effective fuel temperature coefficient of reactivity (Doppler coefficient) is selected with the least negative values. The least negative Doppler coefficient would minimize the core power decrease when 
the fuel temperature rises. The Doppler weighting factor is decided from the axial power offset and Doppler coefficient.

- Moderator temperature coefficient is expressed in the moderator density coefficient in the MARS code analysis. The moderator density coefficient is selected as 0.0 , which is the least moderator temperature coefficient (MTC) value under hot full power conditions. For the LBLOCA analysis, the most conservative moderator density coefficient, which was generated for LBLOCA analysis only, is selected.

- The shutdown reactivity is dependent on the net scram worth available on a reactor trip and the axial power shape. For most transient analyses, the less negative net scram worth is a more conservative value. Thus, the net scram worth is selected with a cycle independent minimum value for the hot full power conditions.

- The axial power offset is selected as +0.3 . This value is the most conservative for the hot full power conditions.

- Effective delayed neutron fraction is selected as the maximum value. The maximum effective delayed neutron fraction delays the power decrease under reactor trip conditions. Thus, the maximum value is selected for a conservative analysis. However, the minimum value is selected in the calculation of reactivity insertion rate for a conservative analysis.

- The decay heat generation rate is calculated from the ANS-73 decay heat curve and $20 \%$ of uncertainty of the decay heat is considered for every transient analysis for conservatism.

\subsection{Loss of Flow Accident}

The complete LOFA can result from a simultaneous loss of electrical power in all reactor coolant pumps. The most possible reason of the simultaneous loss of power is the complete loss of offsite power. Since a loss of offsite power results in a turbine trip that would render the steam dump and bypass systems unavailable, the plant cool-down can only be performed by utilizing the secondary and atmospheric valves. A total loss of forced reactor coolant flow produces a minimum DNBR that could be more severe than any partial loss of a forced reactor coolant flow event. The safety parameter of concern for the loss of reactor coolant flow is the minimum hot channel DNBR. The CE-1 correlation was used for DNBR calculation.

Table 4 shows the event sequences of the complete loss of flow accident. The initiation of LOFA results from the loss of off-site power at 0 seconds. Simultaneously, the turbine is stopped, and a reactor coolant pump flow starts to decrease. At $0.91 \mathrm{sec}$, the reactor is tripped by a low pump speed signal. During the loss of coolant flow, the minimum DNBR is reached at 4.1 seconds, and the value is 1.85 , which has a sufficient margin against the acceptance criterion of 1.3, as shown in Fig. 8. Fig. 9 shows that reactor coolant system pressure is reached to a maximum value at 6.2 seconds. This value is less than $110 \%$ of the design RCS pressure.

\subsection{Large-Break Loss of Coolant Accident}

LBLOCA is one of the representative design basis accidents for an OPR-1000. A hypothetical double-ended guillotine break in a cold leg pipe was considered. The safety injection system of OPR-1000 consists of two 
trains of high pressure safety injection (HPSI) and two trains of low pressure safety injection (LPSI).

In this study, a single failure of the diesel generator was considered. Thus, only one HPSI and one LPSI were activated. The major parameter is the PCT of the hottest fuel rod.

Table 5 shows the event sequences of the LBLOCA. The initiation of LBLOCA is resulted from the doubleended guillotine break of a cold leg pipe at 0.0 seconds. Core power is increased and the pressure of reactor coolant system is decreased. When the RCS pressure reaches the low pressurizer pressure trip setpoint of 12.15 $\mathrm{MPa}$, the reactor is tripped at 6.86 seconds. The accumulator starts to be injected at 17.9 seconds, and the safety injection is activated at 36.9 seconds. Since the MARS code has the best-estimate models and does not follow the conservative 10CFR Appendix $\mathrm{K}$ feature, the overall model uncertainties should be quantified and added in the LBLOCA calculation.

The uncertainty quantification of LBLOCA requires a hundred calculations with a random sampling of the input and model uncertainties. Fortunately, the maximum PCT uncertainty of the RELAP5/MOD3.3 model for an OPR1000 LBLOCA has been already estimated as lower than $200 \mathrm{~K}$. The major LOCA models of MARS are the same as RELAP5/MOD3.3, thus the maximum uncertainty value is assumed to be the same as the RELAP5 model uncertainty. During the LBLOCA, the reference PCT is $947 \mathrm{~K}$, as shown in Fig. 10. If the model uncertainty is added to the reference peak value, the maximum PCT will be $1147 \mathrm{~K}$, which is low enough for the acceptance criterion, 1477 K. Fig. 11 shows the pressure behavior of the reactor coolant system.

\subsection{CEA Ejection Accident}

This accident is defined as the mechanical failure of a control element drive mechanism (CEDM) housing, which results in the ejection of a CEA and its drive shaft. The consequence of this CEA ejection is a rapid positive reactivity insertion with an increase of core power peaking, possibly leading to a localized fuel rod failure. The nuclear excursion is terminated by a Doppler reactivity feedback from the increased fuel temperature, and the core is shut down by the high power reactor trip (high and low setpoint for hot full power (HFP) and hot zero power (HZP), respectively).

The ejected rod worth and hot channel factor $(\mathrm{Fq})$ distortion factor are calculated as Table 6. Since the most conservative state is considered as the end of cycle (EOC) of the 1st cycle, an analysis is performed at the EOC with HFP. The calculated sequence of events corresponding to these limiting events is provided in Table 7. The reactivity, reactor power, fuel and cladding temperature, and the radial average fuel enthalpy transients for the HFP EOC case are presented in Fig. 12, 13, 14 and 15. The reactivity insertion causes a rapid increase in power, and the power increase is terminated by the Doppler feedback. The reactor trip is initiated by a variable overpower reactor trip (VOPT) and the reactor returns to subcritical following the trip. The peak pressure is below $110 \%$ of the design pressure. The peak fuel centerline temperature is $2056 \mathrm{~K}$, which remains below the fuel melting temperature limit of $3003 \mathrm{~K}$. The peak fuel enthalpy derived from the average temperature is 160 $\mathrm{cal} / \mathrm{gm}$, which is low enough for the $230 \mathrm{cal} / \mathrm{gm}$ criteria.

\subsection{Station Blackout}

The SBO event is an accident caused by the loss of all available electric power, including offsite, emergency 
diesel, and alternative AC power. The turbine, coolant pump, and main feedwater are not operated due to a loss of offsite power. None of the HPSIs and LPSIs are available, except for the accumulators. In an SBO event, the continuous leakage of RCS coolant due to the opening of the pressurizer safety valve results in core-uncovery and a rapid increase of the cladding temperature. SBO is classified as a beyond design basis accident and is analyzed with best-estimate methodology (IAEA, 2000).

In the SBO event, the lack of active safety injection causes the cladding and fuel temperatures to increase continuously. The main safety concern is the time at which the radioactive material is released. For the Zircalloy cladding reference fuel, the radioactive material can be released when a coolable geometry is no longer maintained after the cladding failure. On the other hand, for the FCM fuel, the radioactive material can be contained in the fuel pellet for a long time even after the cladding failure. The SiC layer of the TRISO and the $\mathrm{SiC}$ pellet matrix can still be intact and work as barriers. Fig. 16 shows the FCM fuel centerline temperature and cladding temperature. Although the SiC coated Zircalloy cladding fails at 110 minutes, there is 110 more minutes available for operator actions before the start of fuel melting occurs. .

\subsection{LBLOCA without Safety Injection}

The LBLOCA without SI also is analyzed as a beyond-DBA. While one HPSI and one LPSI are assumed to be active in the design-basis LBLOCA, no safety injection system is assumed to be available in this scenario. Without the active safety injections, the core inventory is depleted soon, and fuels heat up rapidly after coreuncovery. The heat-up rate of the Zircalloy conventional fuel is accelerated by the added metal-water-reaction heat. For the conventional $\mathrm{UO}_{2}$ fuel, radioactive material can be released when the $\mathrm{SiC}$ coated Zircalloy cladding fails. On the other hand, the heat-up rate is mild for the FCM fuel; in addition, by virtue of the refractory SiC layer of TRISO and SiC pellet matrix, the radioactive material can be retained longer in the fuel pellet even after the cladding failure.

As shown in Fig. 17, The SiC coated Zircalloy cladding failsd at 573 seconds; however, there are 1215 more seconds available for operator actions before the start of fuel melting occurs.

\section{Conclusion}

To evaluate the feasibility of a FCM fueled core, a preliminary scoping analysis has been performed. In the scoping analysis, 12x12 and 16x16 FCM FA arrays with SS, SiC and SiC coated Zircalloy cladding are compared with the reference $16 \times 16 \mathrm{UO}_{2} / \mathrm{Zr}$ FA of an OPR-1000. According to the scoping evaluations, the most feasible candidate is selected as a 16x16 FCM fuel assembly with SiC coated Zircalloy cladding. For the selected design, safety analyses for limiting DBA and BDBA scenarios were performed to demonstrate the accident tolerance of the FCM fueled core.

The MARS system thermal-hydraulics code is used for the safety analysis using FCM core physics parameters from 3-D neutronics calculation. The preliminary acceptance criteria for the FCM fuel are assumed; however, the final safety criteria should be determined and validated through an extensive experiment program. 
The limiting DBA scenarios are selected as LOFA, LOCA, and CEA ejection accident. The analysis results show that the safety of the FCM fueled core meets the preliminary safety criteria with a sufficient margin. The analysis results of the extreme BDBA scenarios such as LOCA without SI and SBO show that the FCM fuel pellet in a SiC matrix can survive for a long time, which allows operator's mitigation actions.

\section{Acknowledgment}

This study has been performed under the Korea-US International Nuclear Energy Research Initiative (INERI) project supported by Korea Ministry of Science, ICT and Future Planning (MSIP) and US Department of Energy (DOE).

\section{References}

Baba, M., 2013. Fukushima accident: What happened?. Radiation Measurements 55 , 17-21.

Terrani, K. A., Snead, L. L., Gehin, J. C.,2012. Microencapsulated fuel technology for commercial light water and advanced reactor application. Journal of Nuclear Material 427. 209-224.

Lee, W.J., 2013. Fully Ceramic Microencapsulated (FCM) Replacement Fuel for LWRs. I-NERI Technical Annual report. KAERI, ORNL, and USNC.

Lee, W. J., Lee, K. H., Kwon, H., Chun, J. H., Kim, Y. M., 2014. Feasibility of Fully Ceramic Microencapsulated (FCM) replacement fuel assessment for OPR-1000 core fully loaded with FCM fuel assemblies. The $19^{\text {th }}$ Pacific Basin Nuclear Conference (PBNC 2014).

Pappano, P. J., Burchell, T. D., Hunn, J. D., Trammell, M. P., 2008. A novel approach to fabricating fuel compacts for the next generation nuclear plant (NGNP). Journal of Nuclear Material 381. 25-38.

Petti, D. A., Demkowicz, P. A., Maki, J. T., 2012. 3.07 - TRISO-Coated Particle Fuel Performance. Comprehensive Nuclear Materials Volume 3. 131-213.

Stempien, J. D., 2011. Behavior of Triplex Silicon Carbide Fuel Cladding Designs Tested Under Simulated PWR Conditions. Master Thesis, Massachusetts Institute of Technology.

Ott, L. J., Robb, K. R., 2013. Accident Tolerant Fuel/Cladding : Preliminary Reactor DBD Accident Simulations. The 1st ATF Workshop. 24-25 July.

USNRC, 2007. Regulatory Guide 1.206, Combined license applications for nuclear power plants (LWR edition). Office of standards development. U.S. Nuclear Regulatory Commission.

The RELAP5 Code Development Team, 1995. RELAP5/MOD3 CODE MANUAL VOLUME I: CODE STRUCTURE, SYSTEM MODELS, AND SOLUTION METHODS. NUREG/CR-5535, INEL-95/0174 (Formerly EGG-2596) Volume I. Idaho National Engineering Laboratory Lockheed Idaho Technologies Company.

Thurgood, M. J., Kelly, J. M., Guidotti, T. E., Kohrt, R. J., Crowell, K. R., 1983. COBRA/TRAC A Thermalhydraulics Code for Transient Analysis of Nuclear Reactor Vessels and Primary Coolant Systems. NUREG/CR-3046, PNL-4385.

KAERI, 2009. MARS CODE MANUAL VOLUME III: PROGRAMMER'S MANUAL. KAERI/TR- 
3150/2006. Thermal Hydraulic Safety research Department.

Lee, Y. J., Bae, S. W., Chung, B. D., 2003. Validation of one-dimensional module MARS 2.1 computer code by comparing with the RELAP5/MOD3.3 developmental assessment results. KAERI/TR-2411/2003.

Lee, S. W., Kim, H. T., Bang, I. C., 2013. Performance evaluation of UO2/graphene composit fuel and SiC cladding during LBLOCA using MARS-KS. Nuclear Engineering and Design 257. 139-145.

Terrani, K. A., Zinkle, S. J., Snead, L. L., 2014. Advanced oxidation-resistant iron-based alloys for LWR fuel cladding. Journal of Nuclear Material 448. 420-435.

Snead, L. L., 2007. Handbook of SiC properties for fuel performance modeling. Journal of Nuclear Materials 371. 329-377.

USNRC, 1974. Assumptions Used for Evaluating a Control Rod Ejection Accident for Pressurized Water Reactors. NRC Regulatory Guide 1.77.

IAEA, 2000. IAEA Safety Standards Series, Safety of Nuclear Power Plant: Design. No. NS-R-1. 


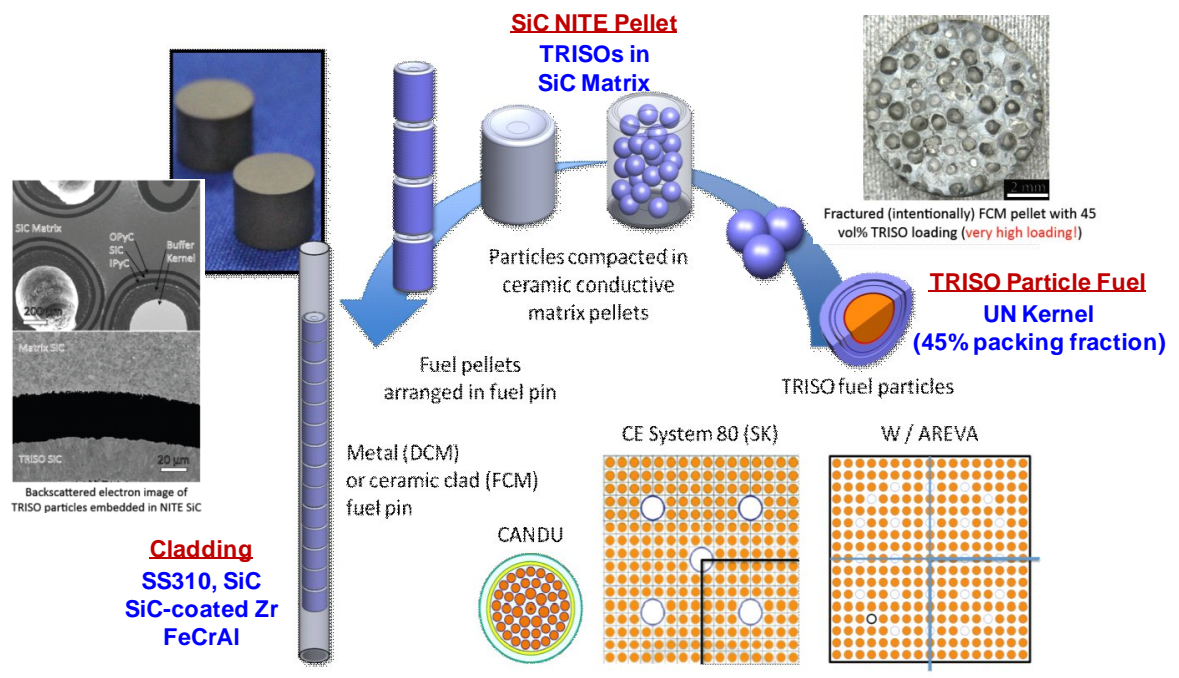

Fig. 1. FCM Fuel Design Concept

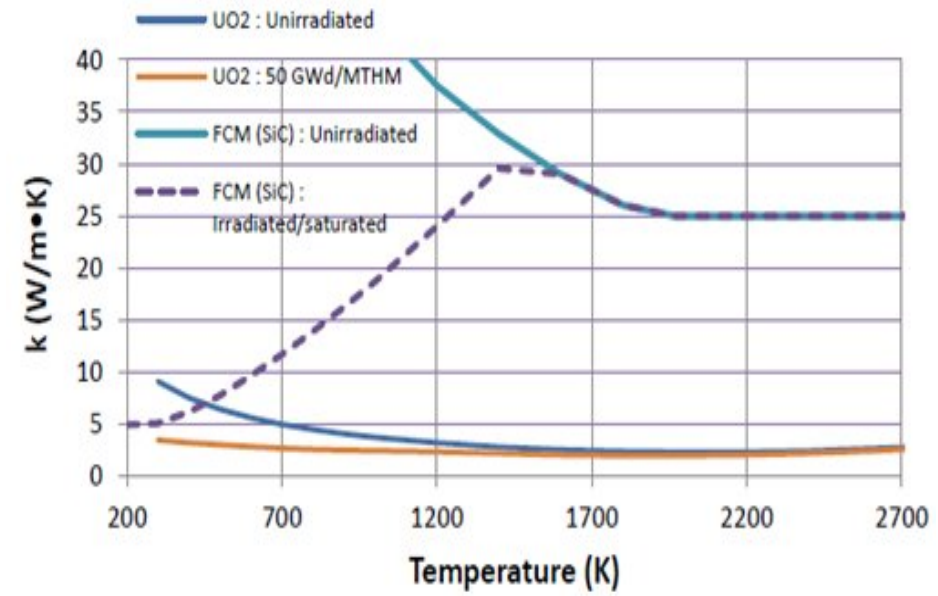

Fig. 2. ORNL experimented data for thermal conductivity of $\mathrm{FCM}$ and $\mathrm{UO}_{2}$ fuels (Ott, 2013) 


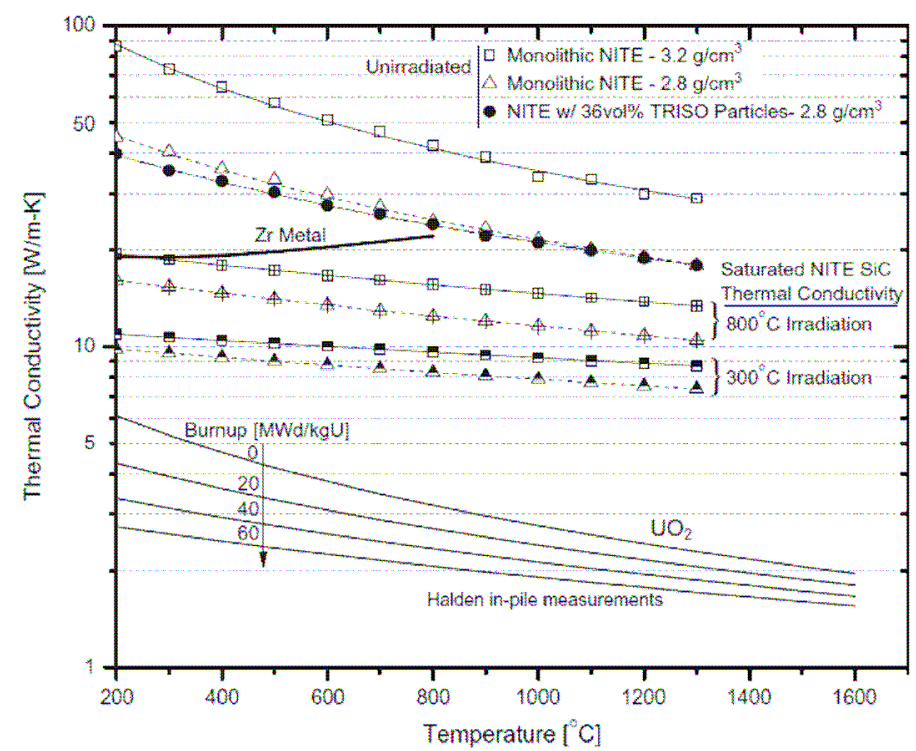

Fig. 3. Thermal conductivity of NITE-based SiC for an FCM fuel matrix (Terrani, 2012)

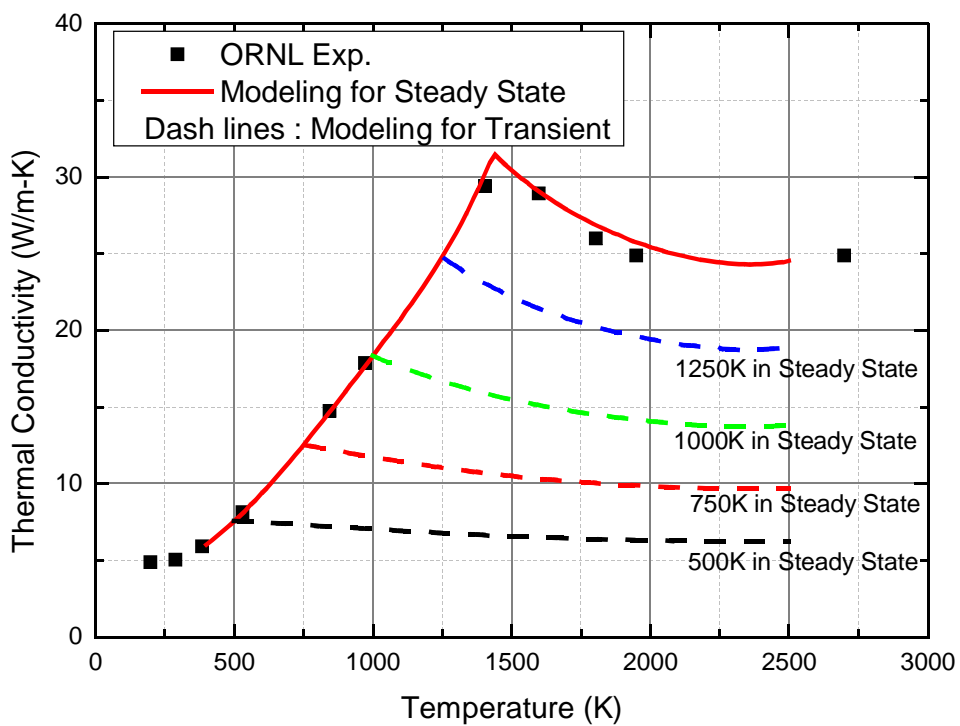

Fig. 4. Thermal Conductivity Prediction Modeling 


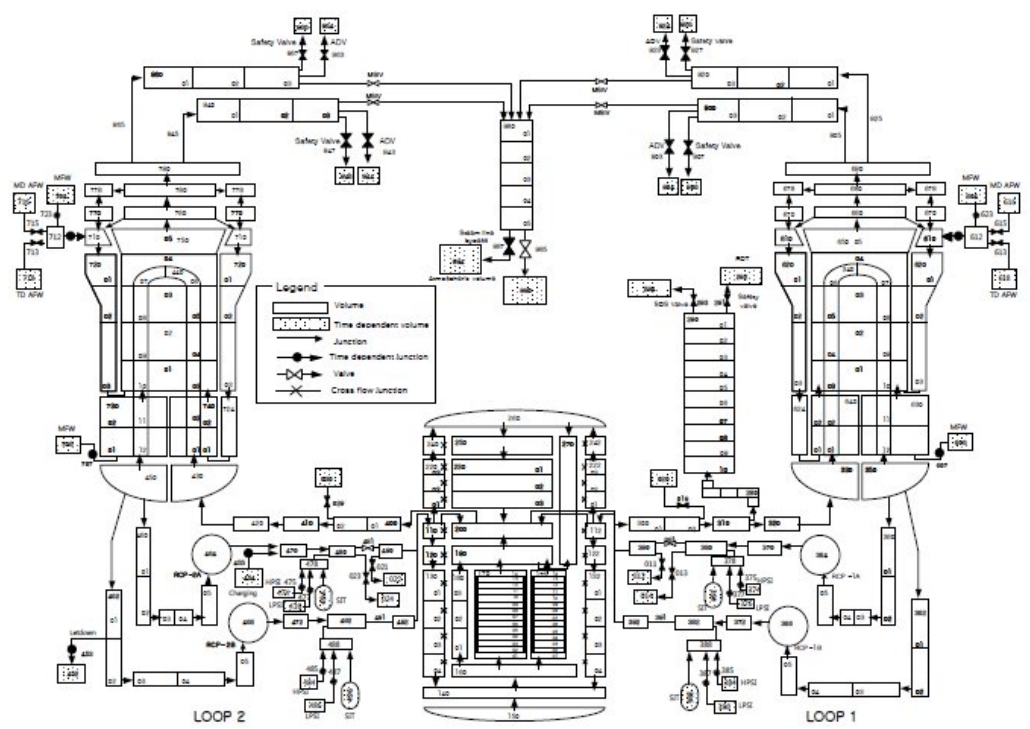

Fig. 5. Nodalization of OPR-1000 for safety analysis

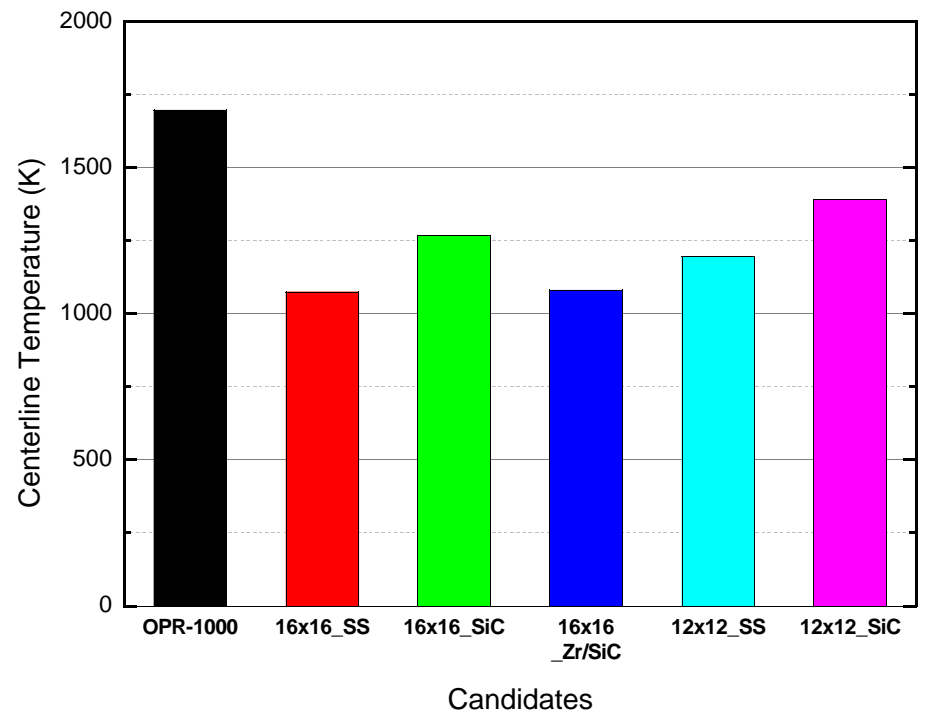

Fig. 6. Centerline Temperatures for Each Candidate 


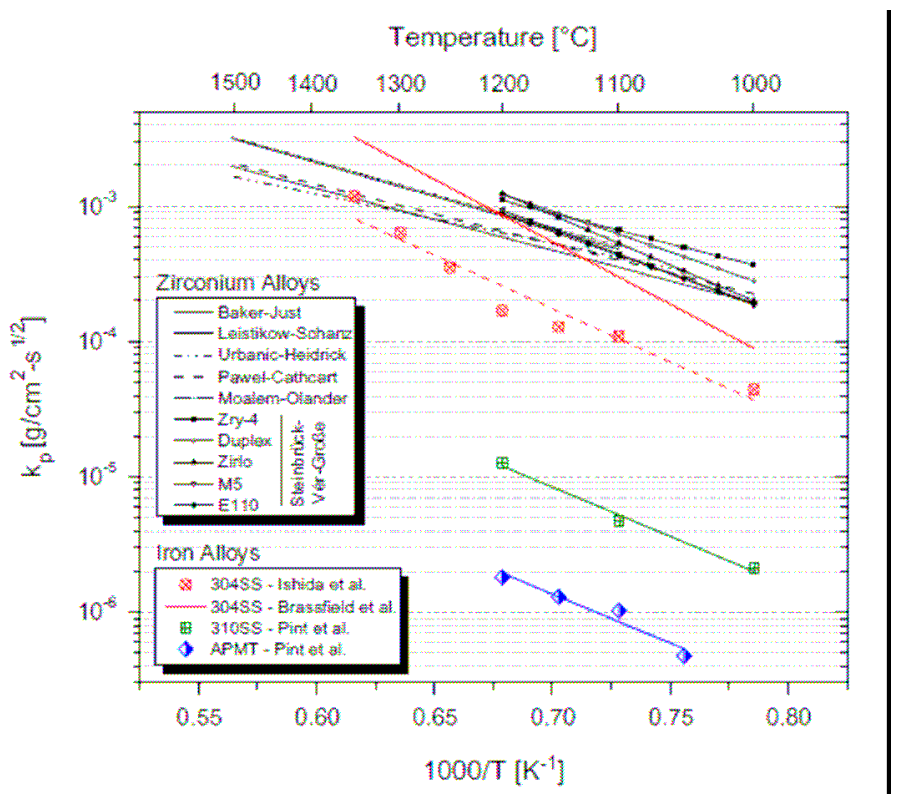

Fig. 7. Oxidation Rate of Cladding Materials (Terrani, 2014)

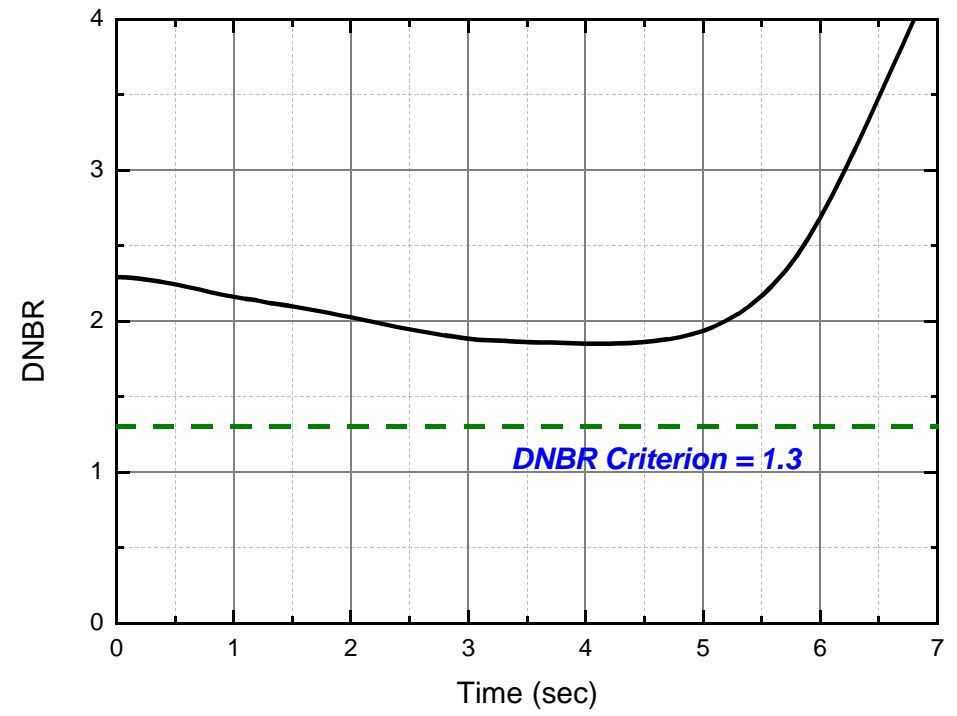

Fig. 8. DNBR for Hottest Rod in Loss of Flow Accident 


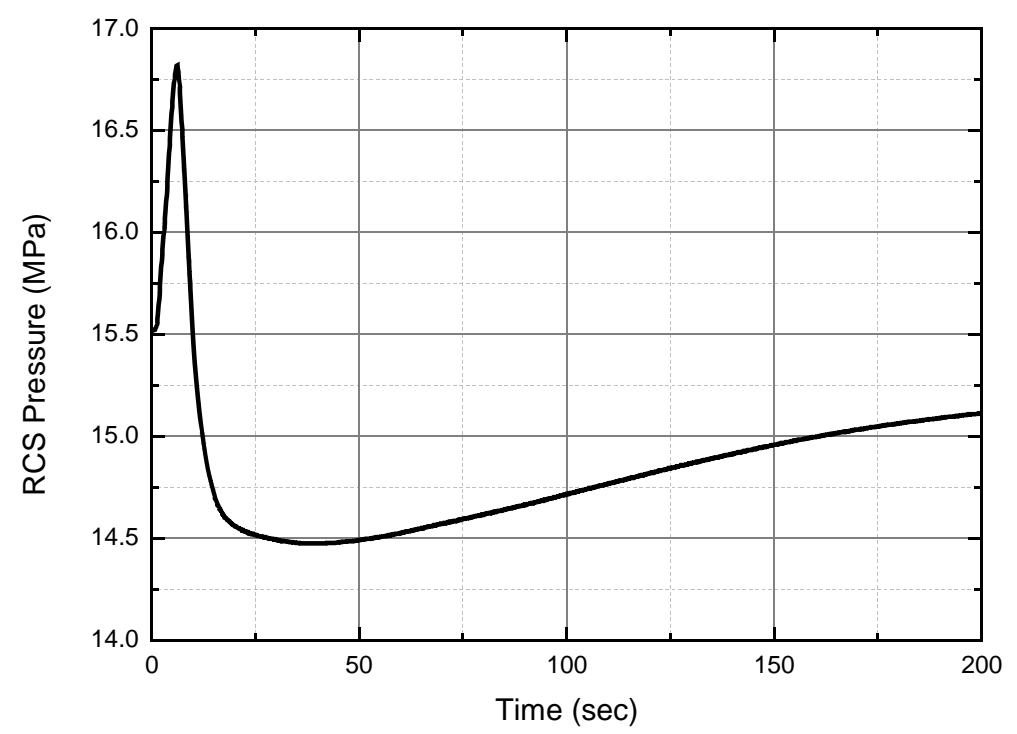

Fig. 9. RCS Pressure in Loss of Flow Accident

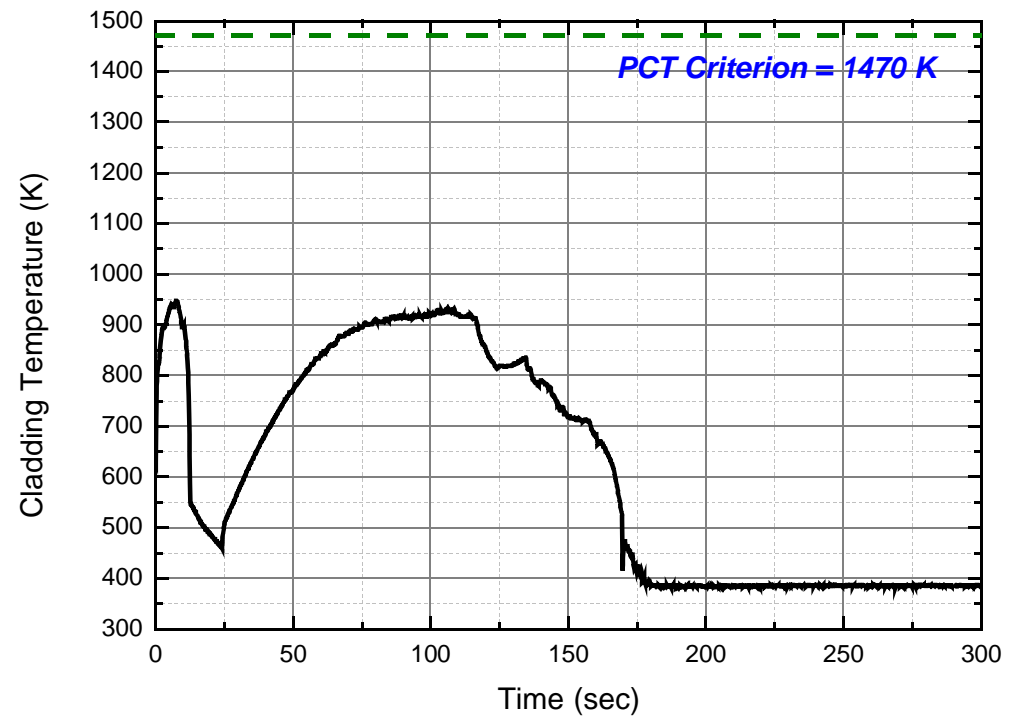

Fig. 10. Cladding Temperature for Hottest Rod in Loss of Coolant Accident 


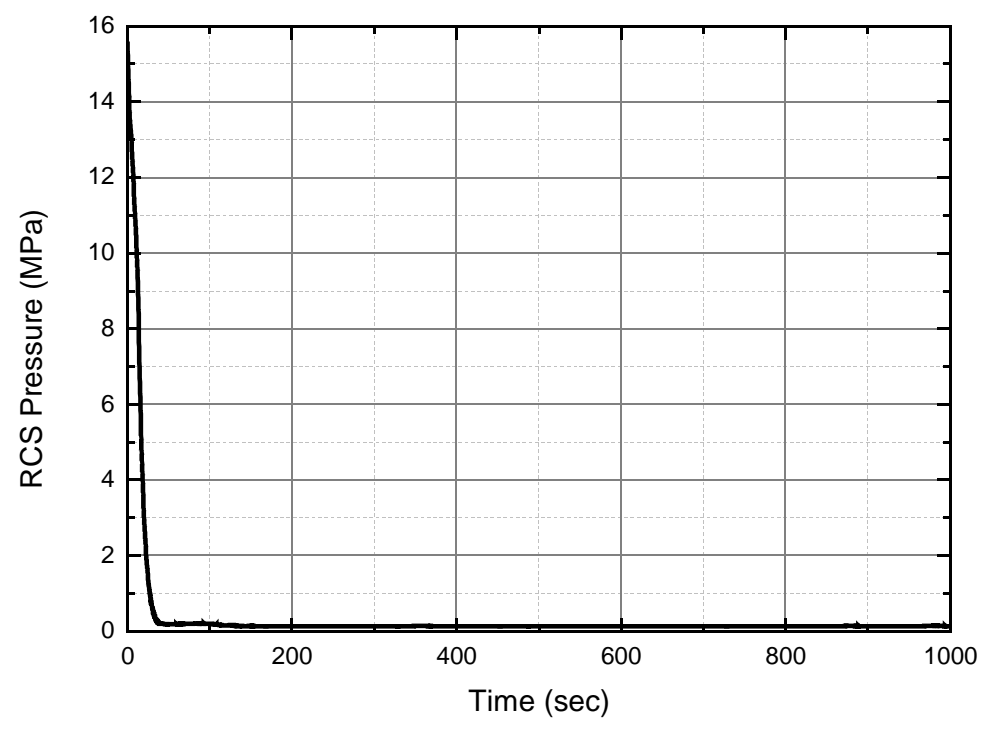

Fig. 11. RCS Pressure Loss of Coolant Accident

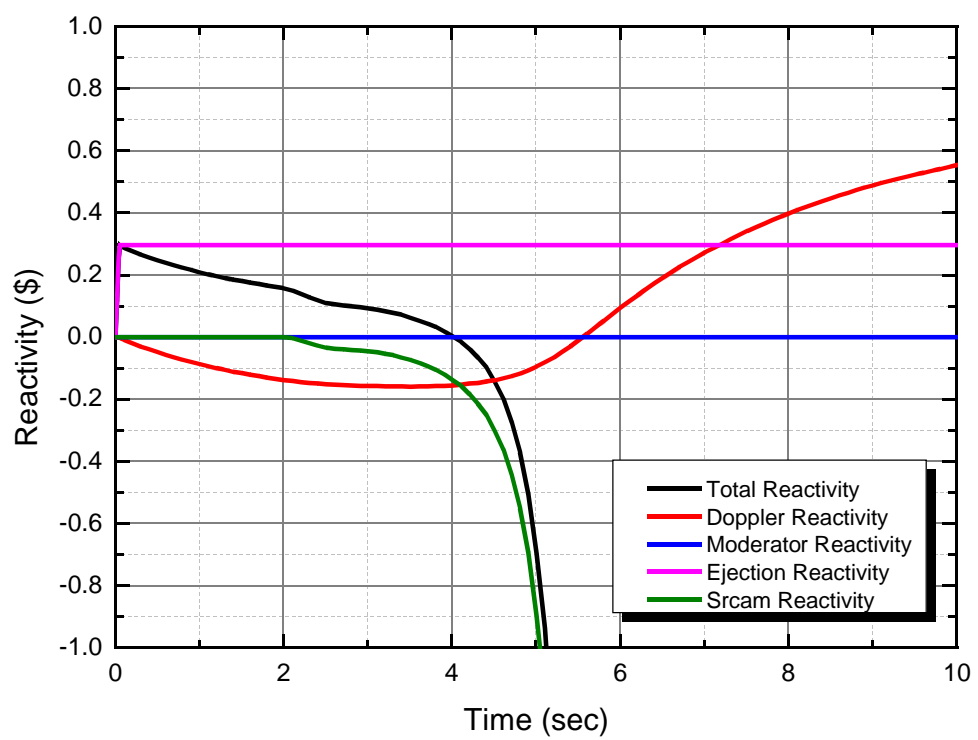

Fig. 12. Reactivity at HFP in CEA Ejection Accident 


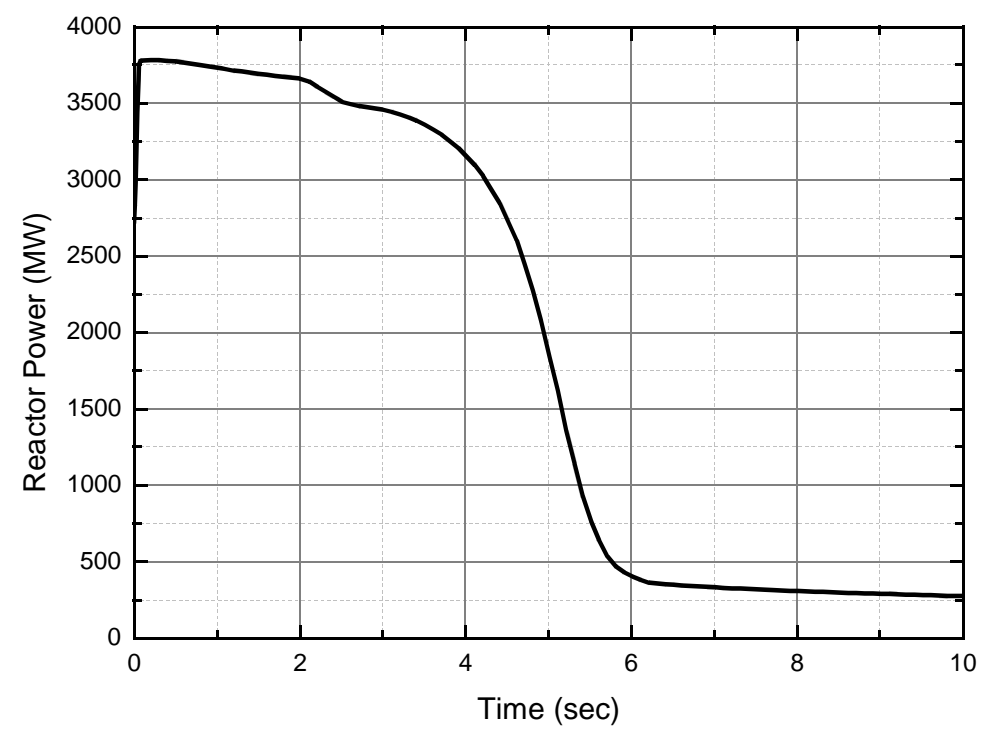

Fig. 13. Reactor Power at HFP in CEA Ejection Accident

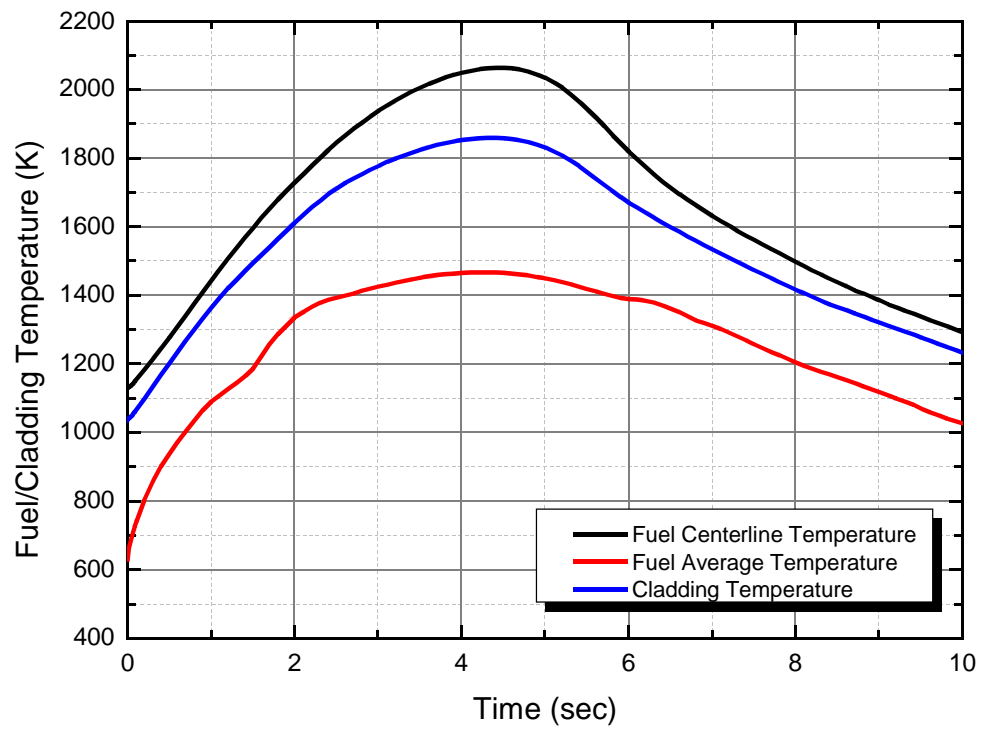

Fig. 14. Fuel and Cladding Temperature at HFP in CEA Ejection Accident 


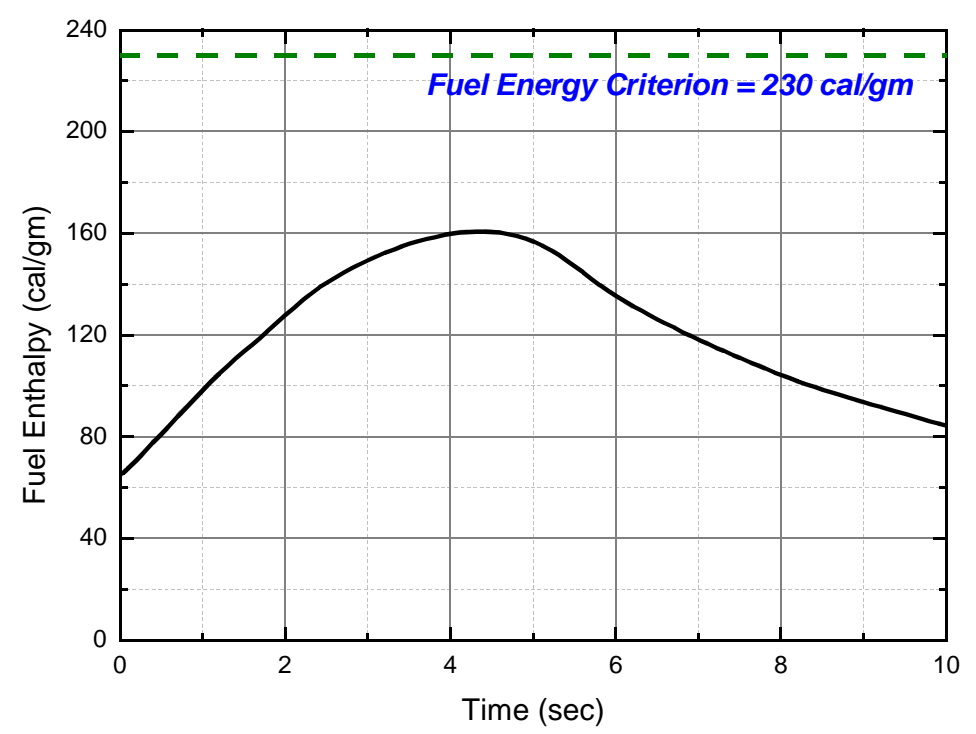

Fig. 15. Fuel Enthalpy at HFP in CEA Ejection Accident

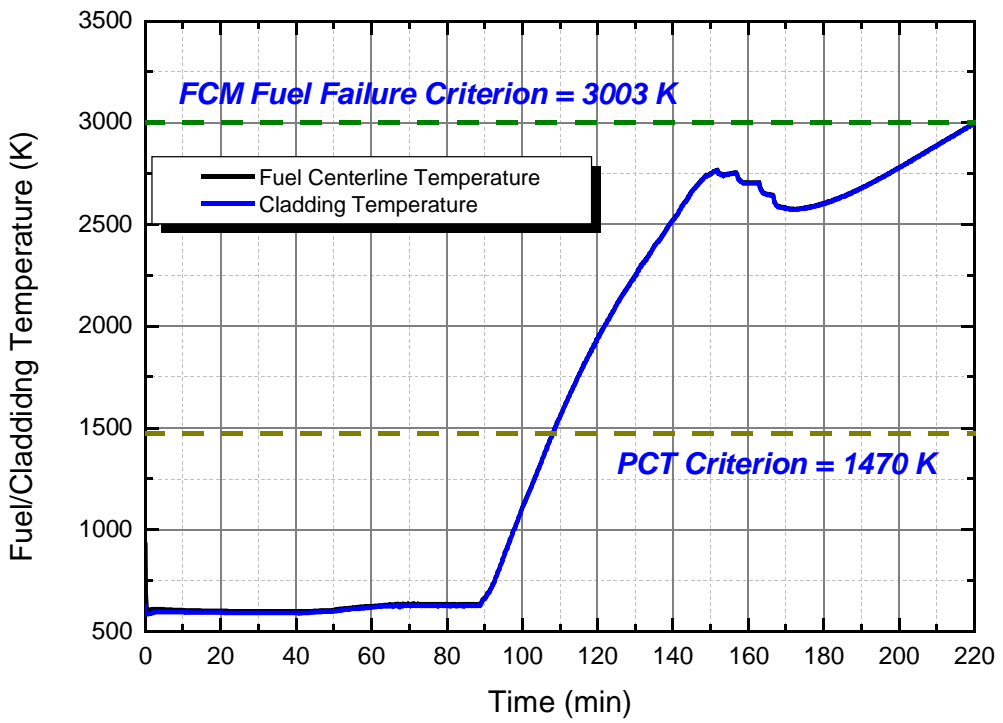

Fig. 16. Fuel and Cladding Temperature for Hottest Rod in Station Blackout 


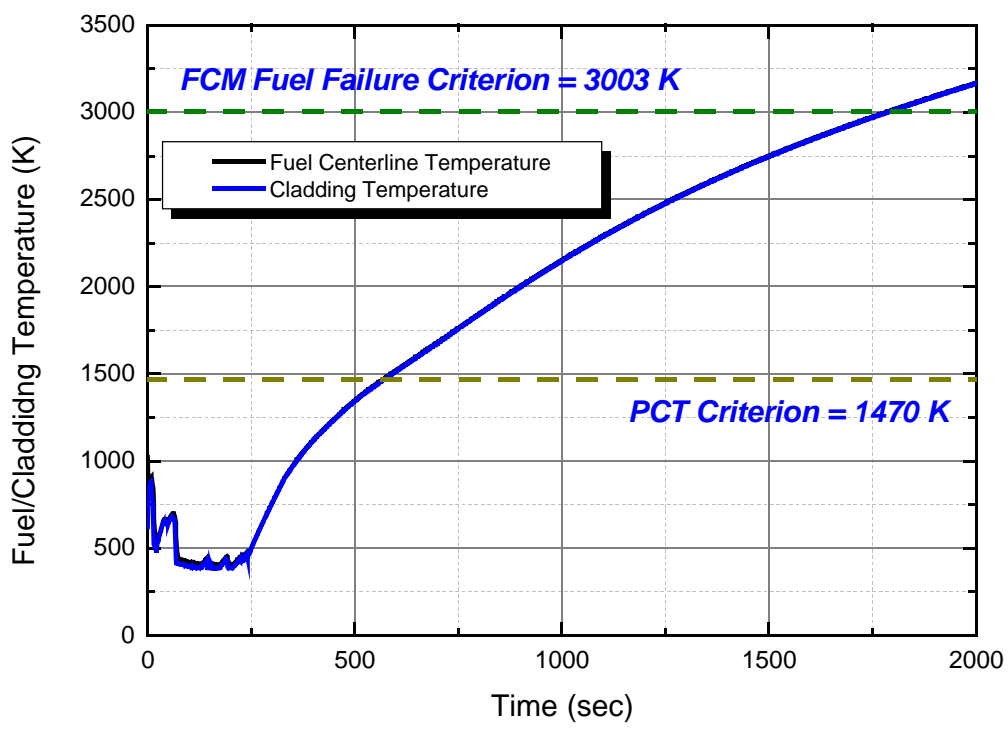

Fig. 17. Fuel and Cladding Temperature for Hottest Rod in LBLOCA without Safety Injection 
Table 1. FCM Fueled Core Design Parameters

\begin{tabular}{|c|c|c|c|c|c|c|c|}
\hline Item & Unit & $\begin{array}{c}16 \times 16 \\
\text { solid }\end{array}$ & $\begin{array}{c}16 \times 16 \\
\mathrm{SS}\end{array}$ & $\begin{array}{c}16 \times 16 \\
\mathrm{SiC}\end{array}$ & $\begin{array}{l}16 \times 16 \\
\mathrm{SiC} / \mathrm{Zr} \\
\end{array}$ & $\begin{array}{c}12 \times 12 \\
\mathrm{SS}\end{array}$ & $\begin{array}{c}12 \times 12 \\
\mathrm{SiC}\end{array}$ \\
\hline Assembly Pitch & $\mathrm{cm}$ & 20.78 & $\leftarrow$ & $\leftarrow$ & $\leftarrow$ & $\leftarrow$ & $\leftarrow$ \\
\hline Cell Pitch & $\mathrm{cm}$ & 1.285 & 1.285 & 1.285 & 1.285 & 1.715 & 1.715 \\
\hline \multicolumn{8}{|l|}{ Fuel Rod } \\
\hline \multicolumn{8}{|l|}{ Pellet/Compact } \\
\hline Material & & $\mathrm{UO} 2$ & $\begin{array}{c}\mathrm{SiC} \\
\text { Matrix }\end{array}$ & $\begin{array}{c}\mathrm{SiC} \\
\text { Matrix }\end{array}$ & $\begin{array}{c}\mathrm{SiC} \\
\text { Matrix }\end{array}$ & $\begin{array}{c}\mathrm{SiC} \\
\text { Matrix }\end{array}$ & $\begin{array}{c}\text { SiC } \\
\text { Matrix }\end{array}$ \\
\hline Density & $\mathrm{g} / \mathrm{cc}$ & 10.176 & 3.18 & 3.18 & 3.18 & 3.18 & 3.18 \\
\hline TRISO Packing Fraction & $\%$ & - & 45 & 45 & 45 & 45 & 45 \\
\hline Pellet Radius & $\mathrm{cm}$ & 0.4095 & 0.4325 & 0.3915 & 0.4325 & 0.6725 & 0.6315 \\
\hline \multicolumn{8}{|l|}{ Clad } \\
\hline Material & & Zry-4 & SS & $\mathrm{SiC}$ & $\begin{array}{c}\text { SiC } \\
\text { coated } \\
\text { Zircalloy }\end{array}$ & SS & $\mathrm{SiC}$ \\
\hline Density & $\mathrm{g} / \mathrm{cc}$ & 6.55 & 8.00 & 3.18 & 8.00 & 8.00 & 3.18 \\
\hline Clad Inner Radius & $\mathrm{cm}$ & 0.4180 & 0.4410 & 0.4000 & 0.4410 & 0.6810 & 0.6400 \\
\hline Clad Outer Radius & $\mathrm{cm}$ & 0.4750 & 0.5000 & 0.5000 & 0.5000 & 0.7400 & 0.7400 \\
\hline Clad Thickness & $\mathrm{cm}$ & 0.0570 & 0.0590 & 0.1000 & 0.0590 & 0.0590 & 0.1000 \\
\hline Gap Thickness & $\mathrm{cm}$ & 0.0085 & $\leftarrow$ & $\leftarrow$ & $\leftarrow$ & $\leftarrow$ & $\leftarrow$ \\
\hline Rod to Rod Spacing & $\mathrm{cm}$ & 0.3350 & 0.2850 & 0.2850 & 0.2850 & 0.2350 & 0.2350 \\
\hline
\end{tabular}

Table 2. Event Categorization and Acceptance Criteria of Fuel Integrity (USNRC, 2007)

\begin{tabular}{|c|c|c|}
\hline $\begin{array}{l}\text { ANS Event } \\
\text { Category }\end{array}$ & $\begin{array}{c}\text { Regulatory } \\
\text { Category }\end{array}$ & $\begin{array}{l}\text { Acceptance criteria for } \\
\text { FCM Fuel / Zr-SiC Clad }\end{array}$ \\
\hline $\begin{array}{l}\text { Moderate } \\
\text { Frequency }\end{array}$ & \multirow{2}{*}{$\mathrm{AOO}$} & \multirow{2}{*}{$\begin{array}{l}\text { No Fuel Failure } \\
\text { - DNBR }>1.3 \\
\text { - P }<110 \% \text { design pressure }\end{array}$} \\
\hline $\begin{array}{l}\text { Infrequent } \\
\text { Incidents }\end{array}$ & & \\
\hline Limiting Faults & DBA & $\begin{array}{l}\text { Coolable Geometry } \\
-\mathrm{T}_{\text {clad }}<1470 \mathrm{~K} \\
\text { - Local Oxidation }<17 \% \\
\text { - PCMI } \\
: \text { Fuel energy }<230 \mathrm{Cal} / \mathrm{g} \\
\text { - No center line melting } \\
: \mathrm{T}_{\mathrm{CL}}<3003 \mathrm{~K}\end{array}$ \\
\hline \multicolumn{2}{|c|}{ Beyond-DBA } & \\
\hline
\end{tabular}


Table 3. Initial Conditions and Input Parameters for a Safety Analysis of FCM Fueled Core

\begin{tabular}{|l|c|}
\hline \multicolumn{1}{|c|}{ Parameter } & Value \\
\hline Initial Core Power, MWt & 2815.0 \\
\hline Initial Core Inlet Coolant Temperature, $\mathrm{K}$ & 567.4 \\
\hline Initial Core Mass Flow Rate, $\mathrm{kg} / \mathrm{sec}$ & 15,566 \\
\hline Initial Pressurizer Pressure, MPa & 15.52 \\
\hline Initial Pressurizer Water Volume, $\mathrm{m}^{3}$ & 23.722 \\
\hline Net Scram Worth on Trip, $\% \triangle \rho$ & 10.98 \\
\hline Moderator Density Coefficient & 0.0 \\
\hline Axial Offset & +0.3 \\
\hline Maximum Radial Peaking Factor & 1.5409 \\
\hline Doppler Reactivity & Least Negative \\
\hline
\end{tabular}

Table 4. Sequence of Events for Loss of Coolant Accident

\begin{tabular}{|c|l|}
\hline Time (seconds) & \multicolumn{1}{|c|}{ Sequence of Event } \\
\hline 0.0 & $\begin{array}{l}\text { Loss of Off-Site Power } \\
- \text { Turbine Trip }\end{array}$ \\
\hline 0.91 & Reactor Trip by Low Pump Speed (94.8\%) Signal \\
\hline 2.91 & Control Rod Drop \\
\hline 4.1 & Minimum DNBR \\
\hline 6.2 & Maximum RCS Pressure \\
\hline & End of Event \\
\hline
\end{tabular}


Table 5. Sequence of Events for Large-Break Loss of Coolant Accident

\begin{tabular}{|c|l|}
\hline Time (seconds) & \multicolumn{1}{|c|}{ Sequence of Event } \\
\hline 0.0 & Guillotine Break of Cold Leg Pipe \\
\hline 6.86 & Reactor Trip by Low Pressurizer Pressure (12.15 MPa) Signal \\
\hline 7.8 & Maximum Peak Cladding Temperature \\
\hline 8.86 & Control Rod Drop \\
\hline 17.9 & Injection of Accumulator \\
\hline 36.9 & Activation of Safety Injection \\
\hline & End of Event \\
\hline
\end{tabular}

Table 6. Ejected Rod Worth (ERW) and Fq distortion factors at various states.

\begin{tabular}{|c|c|c|c|}
\hline & Burnup & ERW (\$) & Fq Distortion Factor \\
\hline \multirow{2}{*}{ Cycle 1 } & BOC & 0.213736338 & 1.4389 \\
\cline { 2 - 4 } & EOC & 0.296017618 & 1.6195 \\
\hline \multirow{2}{*}{ Cycle 5 } & BOC & 0.192957343 & 1.3046 \\
\cline { 2 - 4 } & EOC & 0.242605698 & 1.4655 \\
\hline
\end{tabular}

Table 7. The Sequence of Events for CEA Ejection Accident

\begin{tabular}{|c|l|}
\hline Time $(\mathrm{sec})$ & \multicolumn{1}{c|}{ Sequence of Event } \\
\hline 0.0 & CEA Ejection \\
\hline 0.0 & DNB at Hot Spot (Assumption) \\
\hline 0.05 & Full ejection of CEA \\
\hline 0.052 & Reactor Trip by Variable Overpower (127\%) Signal \\
\hline 0.2 & Peak Reactor Power (138\%) \\
\hline 2.05 & Control Rod Drop \\
\hline 4.2 & Maximum Fuel Temperature (Enthalpy) \\
\hline & End of Event \\
\hline
\end{tabular}




\section{CURRICULUM VITAE}

\section{Personal Details}

Name and Surname

: Ji-Han Chun

Date of Birth : 22/December/1970

Marital Status

: Married

Number of Children : One

Nationality

: South Korea

Religion

: Christianity

\section{Higher Education}

March, 1989 - February, 1993

Kyung-Hee University, Korea (Bachelor of Engineering in Nuclear Engineering)

March, 1993.3 - February, 1996

Seoul National University, Korea (Master of Engineering in Nuclear Engineering)

March, 1996.3 - February, 2002

Seoul National University, Korea (Ph.D. in Nuclear Engineering)

\section{Current Position}

Principal Researcher

SMART Development Division

Small Reactor Development Group

Korea Atomic Energy Research Institute

Daedeok-daero 989-111, Yuseong-gu, Daejeon, 305-353, KOREA

Tel: 82-42-868-8915, Fax: 82-42-868-8990

\section{Professional Experience}

March, 2002 - August, 2002

Post-Doc. (Korea Atomic Energy Research Institute)

September, 2002 - February, 2005

Assistant Professor (Yanbian University of Science \&Technology in China)

March, 2006 - August, 2006

Exchange Professor (China Three Gorges University in China)

February, 2005 - June, 2007

Associate Professor (Yanbian University of Science \&Technology in China)

September, 2007 - October, 2009

Research Professor (Seoul National University)

\section{Professional Activities}

December, 2006

Reviewer, International Journal of Heat and Mass Transfer, Elsevier

October, 2011 
Reviewer, International Journal of Heat and Mass Transfer, Elsevier

September, 2014

Reviewer, Nuclear Engineering and Technology, KNS

Honors and Awards

December, 2007

Listed on the Who's Who in Science and Engineering, 10th Anniversary (2008-2009)

Edition, Marquis Who's Who, 2007

Membership

Korean Nuclear Society (Life Member, 2007-) 